\title{
AXIAL STRENGTH OF CFST COLUMNS CONSIDERING CONCRETE AGE
}

\author{
Hai-Yang Wang and Xiao-Xiong Zha* \\ Shenzhen Graduate School, Harbin Institute of Technology, Shenzhen 518055, PR China \\ *(Corresponding author: E-mail: zhahero@126.com and wangsea0510@126.com)
}

Received: 8 September 2012; Revised: 21 November 2012; Accepted: 13 March 2013

\begin{abstract}
Concrete filled steel tube (CFST) columns are used increasingly in high-rise buildings in China. During the rapid construction of high-rise buildings, concrete age is an important factor which will affect the composite axial strength. In this paper, based on the theory of elasticity, a formula is proposed to predict the composite axial strength of CFST considering the concrete age. For the most common use the parameters in the formula are simplified and calibrated by existing test results. Finally the experiments of the ultimate bearing capacity of CFST columns considering concrete age changes are carried out and the FE method is also adopted to validate the formula results. The results show that the formula can be used satisfactorily in predicting the strength of CFST columns considering concrete age.
\end{abstract}

Keywords: CFST, composite strength, concrete age, axial strength

\section{INTRODUCTION}

The concrete filled steel tube (CFST) structure is widely used now around the world because of its superior property on mechanics, fire resistance, anti seismic capacity as well as its cost effective construction. Extensive experimental and theoretical investigations on the CFST have been carried out [1-8]. In recent years, more and more high-rise buildings are constructed using CFST columns mentioned by Fu [9], Fan [10] and Duan [11]. The advantage is to adopt rapid construction which the inside concrete is not fully hardened during the construction and the building is be set up by the outside steel tube frame. This kind of construction method can greatly reduce the time but also bring a problem that the composite strength of CFST column may be different being of the earlier age of concrete.

On the influence of concrete age, Tan and Qi [12] worked systematically by testing the effect of creep on columns under axially compressive loads. Nakai et al. [13] and Terry et al. [14] tested the creep of CFST columns and plain concrete to investigate the influence of the reinforcement on the concrete creep. Ichinose et al. [15], Kwon et al. [16] and Acar [17] also reported a series of tests to obtain creep coefficients of CFST columns. But nearly all of the works are about the aging effect of hardened concrete and there is little attention paid to the research on the aging effect of hardening CFST column.

In this paper, the aging effect of un-fully hardened concrete will be studied on the composite strength of CFST columns and a formula will be proposed based on the theory of elasticity by using the superimposition method and test results. Independent experiments and FE method are also adopted to validate the formula. 


\section{THEORY ANALYSIS}

\subsection{Superimposition method}

In order to determine the formula of composite strength of CFST columns under axial compression, the elastic analysis is adopted. The CFST column can be equivalently divided into two parts. i.e., the steel tube and the concrete part, and the axial compression process can be divided into two steps. i.e., uniaxial compression of each part and plane strain problem according to $\mathrm{Yu}$ [18]. In the uniaxial compression step, two parts are deformed individually as the uniform longitudinal strain. In the second step, there will be the interaction load between the two parts but the longitudinal strain of each part keeps constant which is the plane strain problem, shown in Figure 1.

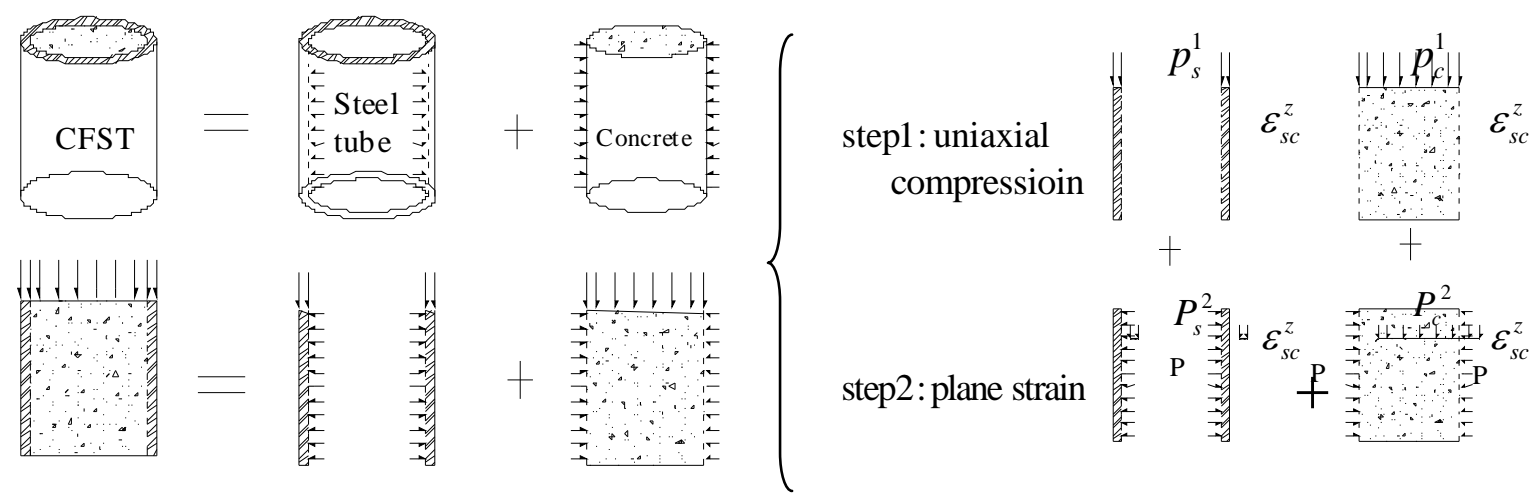

Figure 1. Superimposition Method of CFST under Axial Compression

\subsection{Elastic Analysis}

Assume that the longitudinal strain of the CFST is $\varepsilon_{s c}^{z}(t)$ under the compression load, as a whole. The longitudinal strains in the steel tube $\varepsilon_{s}^{z}(t)$ and the concrete $\varepsilon_{c}^{z}(t)$ should be the same, then

$$
\varepsilon_{s}^{z}(t)=\varepsilon_{c}^{z}(t)=\varepsilon_{s c}^{z}(t)
$$

Step 1: The uniaxial compression stage

In this stage, because of the no interactions between steel and concrete, steel tube and concrete cylinder are unrestrained axisymmetric deformation. According to the generalized Hooke's law the radial strains are:

$$
\begin{aligned}
& \varepsilon_{c}^{r}(t)=-v_{c}(t) \varepsilon_{s c}^{z}(t) \\
& \varepsilon_{s}^{r}(t)=-v_{s} \varepsilon_{s c}^{z}(t)
\end{aligned}
$$

In which, $v_{c}(t)$ is the Poisson's ratio of concrete at age $t$, and $v_{s}$ is the Poisson's ratio of steel. According to Budynas [19], when the radius at the interface surface is $r$, the radial displacements $u_{c}^{1}(t)$ at the outside surface of the concrete cylinder and $u_{s}^{1}$ at the inside surface of the steel tube, are respectively, 


$$
\begin{aligned}
& u_{c}^{1}(t)=r \varepsilon_{c}^{r}(t)=-v_{c}(t) r \varepsilon_{s c}^{z}(t) \\
& u_{s}^{1}(t)=r \varepsilon_{s}^{r}(t)=-v_{s} r \varepsilon_{s c}^{z}(t)
\end{aligned}
$$

So the respective longitudinal stresses of the concrete $\sigma_{c}^{1}(t)$ and the steel $\sigma_{s}^{1}(t)$ are,

$$
\begin{aligned}
& \sigma_{c}^{1}(t)=E_{c}(t) \varepsilon_{c}^{z}(t)=E_{c}(t) \varepsilon_{s c}^{z}(t) \\
& \sigma_{s}^{1}(t)=E_{s} \varepsilon_{s}^{z}(t)=E_{s} \varepsilon_{s c}^{z}(t)
\end{aligned}
$$

In which, $E_{c}(t)$ is the elastic modulus of concrete at age $t$, and $E_{s}$ is the elastic modulus of steel.

Step 2: The plane strain stage

In this stage the longitudinal strain is constant and there is the interactive stress $P$ acting between the inside surface of the steel tube and the outside surface of the concrete. According to the theory of elasticity [20], the radial displacements of the concrete cylinder at the outside surface $u_{c}^{2}(t)$, and the radial displacements of the steel tube at the inside surface $u_{s}^{2}$ can be calculated respectively,

$$
\begin{aligned}
& u_{c}^{2}(t)=-\frac{r^{2} P}{\frac{E_{c}(t)}{1-v_{c}^{2}(t)} r^{2}}\left(1-\frac{v_{c}(t)}{1-v_{c}(t)}\right) r=-\frac{\left(1+v_{c}(t)\right)\left(1-2 v_{c}(t)\right)}{E_{c}(t)} r P \\
& u_{s}^{2}=\frac{\left(1+v_{s}\right) r^{2} P}{E_{s}\left(R^{2}-r^{2}\right)}\left[\frac{R^{2}}{r}+\left(1-2 v_{s}\right) r\right]
\end{aligned}
$$

In which, $R$ is the radius at the outside surface of the steel tube.

Step 3: Superimposition results

Assume that the interfaces are ideal and continuous at the interfaces of the steel tube and concrete part. So the radial displacements of steel part and the concrete part should be same at the interfaces,

$u_{c}^{1}(t)+u_{c}^{2}(t)=u_{s}^{1}+u_{s}^{2}$

Introducing Eqs. 4, 5, 8 and 9 into Eq. 10 yields the interactive stress $P$ at the interface,

$$
P=\frac{-\left(v_{c}(t)-v_{s}\right) \varepsilon_{s c}^{z}(t)}{\frac{\left(1+v_{c}(t)\right)\left(1-2 v_{c}(t)\right)}{E_{c}(t)}+\frac{\left(1+v_{s}\right)}{E_{s}\left(R^{2}-r^{2}\right)}\left[R^{2}+r^{2}\left(1-2 v_{s}\right)\right]}
$$

From the elastic solution from Sadd [20], the longitudinal stresses caused by $P$ in the concrete part $\sigma_{c}^{2}(t)$, and the steel tube $\sigma_{s}^{2}(t)$, are,

$$
\begin{gathered}
\sigma_{c}^{2}(t)=-2 v_{c}(t) P \\
\sigma_{s}^{2}(t)=\frac{2 v_{s} r^{2}}{R^{2}-r^{2}} P
\end{gathered}
$$


Hence, the total longitudinal stresses in the concrete and the steel tube are, respectively,

$$
\begin{aligned}
& \sigma_{c}(t)=\sigma_{c}^{1}(t)+\sigma_{c}^{2}(t)=E_{c}(t) \varepsilon_{s c}^{z}(t)-2 v_{c}(t) P \\
& \sigma_{s}(t)=\sigma_{s}^{1}+\sigma_{s}^{2}=E_{s} \varepsilon_{s c}^{2}(t)+\frac{2 v_{s} r^{2}}{R^{2}-r^{2}} P
\end{aligned}
$$

Introducing Eq. 11 into Eq. 14 and Eq. 15, the equivalent uniform stress distribution $\sigma_{s c}(t)$ over the cross section of the CFST is,

$$
\sigma_{s c}(t)=\frac{A_{s} \sigma_{s}(t)+A_{c} \sigma_{c}(t)}{A_{s c}}
$$

Thus,

$$
\sigma_{s c}(t)=\left[1+\frac{2\left(v_{c}-v_{s}\right)^{2} \alpha \sigma_{s}^{1} / \sigma_{c}^{1}(t)}{\left[\left(1-2 v_{c}\right)\left(1+v_{c}\right) \alpha \sigma_{s}^{1} / \sigma_{c}^{1}(t)+2\left(1-v_{s}^{2}\right)+\left(1+v_{s}\right) \alpha\right]\left(1+\alpha \sigma_{s}^{1} / \sigma_{c}^{1}(t)\right)}\right]\left[(1-\beta) \sigma_{c}^{1}(t)+\beta \sigma_{s}^{1}\right]
$$

Replacing all terms containing Poisson's ratios of steel and concrete by $A, B$ and $C$, Eq. 17 can be written as below,

$$
\sigma_{s c}(t)=\left[1+\frac{\alpha \sigma_{s}^{1} / \sigma_{c}^{1}(t)}{\left[A+B \alpha \sigma_{s}^{1} / \sigma_{c}^{1}(t)+C \alpha\right]\left(1+\alpha \sigma_{s}^{1} / \sigma_{c}^{1}(t)\right)}\right]\left[(1-\beta) \sigma_{c}^{1}(t)+\beta \sigma_{s}^{1}\right]
$$

where, $\quad A=\frac{\left(1-v_{s}^{2}\right)}{\left(v_{c}-v_{s}\right)^{2}}, B=\frac{\left(1-2 v_{c}\right)\left(1+v_{c}\right)}{2\left(v_{c}-v_{s}\right)^{2}}, C=\frac{\left(1+v_{s}\right)}{2\left(v_{c}-v_{s}\right)^{2}}, \beta=\alpha /(1+\alpha)$.

\subsection{Composite Strength of the CFST and Further Modification}

In order to obtain the composite strength of CFST column in inelastic state, it is assumed that the strength of the steel and the concrete are reached simultaneously and introducing the strength of steel and concrete $f_{y}, f_{c k}(t)$ and parameter $\xi_{s c}(t)=\alpha f_{y} / f_{c k}(t)$. So,

$$
f_{s c}(t)=\left[1+\frac{\xi_{s c}(t)}{\left[A+B \xi_{s c}(t)+C \alpha\right]\left(1+\xi_{s c}(t)\right)}\right]\left[(1-\beta) f_{c k}(t)+\beta f_{y}\right]
$$

The influence of concrete age on concrete Poisson's ratio is very little according to Oluokun et al. [21] and Carmichael [22], so the concrete Poisson's ratio can be determined by test results of hardened CFST column which is at the age of 28 days. To statistically obtain estimated values of $A, B$, and $C$, standard regression analysis is carried out on the basis of a rich collection of test results from O'Shea et al. [3] and Kenji et al. [23]. Finally the values of the three constants are $A=2.0, B=0.01, C=0.2$ as showing Table 1 and the results agree well. 
Table 1. Comparison of the Analytical and the Test Results

\begin{tabular}{|c|c|c|c|c|c|c|c|c|c|}
\hline \multirow[b]{2}{*}{ Ref. } & \multirow[b]{2}{*}{ No. } & \multirow[b]{2}{*}{ Numbering } & \multicolumn{2}{|c|}{ Geometric parameters } & \multicolumn{2}{|c|}{$\begin{array}{c}\text { material } \\
\text { parameters }\end{array}$} & \multicolumn{2}{|c|}{$\begin{array}{l}\text { Ultimate } \\
\text { force }\end{array}$} & \multirow{2}{*}{$\begin{array}{l}\text { ratio } \\
N_{\mathrm{T}} / N_{c}\end{array}$} \\
\hline & & & $\begin{array}{r}\text { External } \\
\text { diameter } \\
D / \mathrm{mm}\end{array}$ & $\begin{array}{c}\text { Steel } \\
\text { thickness } \\
T / \mathrm{mm}\end{array}$ & $\begin{array}{c}f_{y} \\
/ \mathrm{Mpa}\end{array}$ & $\begin{array}{c}f_{c k} \\
/ \mathrm{Mpa}\end{array}$ & $\begin{array}{c}\text { Test } \\
N_{\mathrm{T}} / \mathrm{k} \\
\mathrm{N}\end{array}$ & $\begin{array}{c}\text { Calc } \\
N_{c} / \mathrm{k} \\
\mathrm{N}\end{array}$ & \\
\hline \multirow{12}{*}{ [3] } & 1 & S30CS50B & 165 & 2.8 & 363.3 & 48.3 & 1662 & 1744 & 1.05 \\
\hline & 2 & S20CS50A & 190 & 1.9 & 256.4 & 41 & 1678 & 1556 & 0.93 \\
\hline & 3 & S16CS50B & 190 & 1.5 & 306.1 & 48.3 & 1695 & 1739 & 1.03 \\
\hline & 4 & S12CS50A & 190 & 1.1 & 185.7 & 41 & 1377 & 1322 & 0.96 \\
\hline & 5 & S10CS50A & 190 & 0.9 & 210.7 & 41 & 1350 & 1303 & 0.97 \\
\hline & 6 & S30CS80A & 165 & 2.8 & 363.3 & 80.2 & 2295 & 2381 & 1.04 \\
\hline & 7 & S20CS80B & 190 & 1.9 & 256.4 & 74.7 & 2592 & 2473 & 0.95 \\
\hline & 8 & S16CS80A & 190 & 1.5 & 306.1 & 80.2 & 2602 & 2615 & 1.00 \\
\hline & 9 & S12CS80A & 190 & 1.1 & 185.7 & 80.2 & 2295 & 2407 & 1.05 \\
\hline & 10 & S10CS80B & 190 & 0.9 & 210.7 & 74.7 & 2451 & 2241 & 0.91 \\
\hline & 11 & S30CS10A & 165 & 2.8 & 363.3 & 108 & 2673 & 2935 & 1.10 \\
\hline & 12 & S20CS10A & 190 & 1.9 & 256.4 & 108 & 3360 & 3379 & 1.01 \\
\hline \multirow[t]{3}{*}{ [3] } & 13 & S16CS10A & 190 & 1.5 & 306.1 & 108 & 3260 & 3378 & 1.04 \\
\hline & 14 & S12CS10A & 190 & 1.1 & 185.7 & 108 & 3058 & 3176 & 1.04 \\
\hline & 15 & S10CS10A & 190 & 0.9 & 210.7 & 108 & 3070 & 3168 & 1.03 \\
\hline \multirow{21}{*}{ [23] } & 16 & CC4-A-2 & 149 & 3 & 308 & 21.5 & 941 & 971 & 1.03 \\
\hline & 17 & CC4-A-4-1 & 149 & 3 & 308 & 33.1 & 1064 & 1159 & 1.09 \\
\hline & 18 & CC4-A-4-2 & 149 & 3 & 308 & 33.1 & 1080 & 1159 & 1.07 \\
\hline & 19 & CC4-A-8 & 149 & 3 & 308 & 61.2 & 1781 & 1610 & 0.90 \\
\hline & 20 & CC4-C-2 & 301 & 3 & 279 & 21.5 & 2382 & 2629 & 1.10 \\
\hline & 21 & CC4-C-4-1 & 300 & 3 & 279 & 33.6 & 3277 & 3438 & 1.05 \\
\hline & 22 & CC4-C-4-2 & 300 & 3 & 279 & 33.6 & 3152 & 3438 & 1.09 \\
\hline & 23 & CC4-C-8 & 301 & 3 & 279 & 63.8 & 5540 & 5522 & 1.00 \\
\hline & 24 & CC4-D-2 & 450 & 3 & 279 & 21.5 & 4415 & 5069 & 1.15 \\
\hline & 25 & CC4-D-4-1 & 450 & 3 & 279 & 33.6 & 6870 & 6944 & 1.01 \\
\hline & 26 & CC4-D-4-2 & 450 & 3 & 279 & 33.6 & 6985 & 6944 & 0.99 \\
\hline & 27 & CC4-D-8 & 450 & 3 & 279 & 67.6 & 11665 & 12213 & 1.05 \\
\hline & 28 & CC6-A-2 & 122 & 4.5 & 576 & 21.5 & 1509 & 1655 & 1.10 \\
\hline & 29 & CC6-A-4-1 & 122 & 4.5 & 576 & 33.1 & 1657 & 1771 & 1.07 \\
\hline & 30 & CC6-A-4-2 & 122 & 4.5 & 576 & 33.1 & 1663 & 1771 & 1.06 \\
\hline & 31 & CC6-A-8 & 122 & 4.5 & 576 & 61.2 & 2100 & 2052 & 0.98 \\
\hline & 32 & CC6-C-2 & 239 & 4.5 & 507 & 21.5 & 3035 & 3429 & 1.13 \\
\hline & 33 & CC6-C-4-1 & 238 & 4.5 & 507 & 33.1 & 3583 & 3890 & 1.09 \\
\hline & 34 & CC6-C-4-2 & 238 & 4.5 & 507 & 33.1 & 3647 & 3890 & 1.07 \\
\hline & 35 & CC6-C-8 & 238 & 4.5 & 507 & 61.2 & 5578 & 5044 & 0.90 \\
\hline & 36 & CC6-D-2 & 361 & 4.5 & 525 & 21.5 & 5633 & 6088 & 1.08 \\
\hline
\end{tabular}




\begin{tabular}{|c|c|c|c|c|c|c|c|c|c|}
\hline 37 & CC6-D-4-1 & 361 & 4.5 & 525 & 33.6 & 7260 & 7266 & 1.00 \\
\hline 38 & CC6-D-4-2 & 360 & 4.5 & 525 & 33.6 & 7045 & 7237 & 1.03 \\
\hline 39 & CC6-D-8 & 360 & 4.5 & 525 & 67.6 & 11505 & 10526 & 0.91 \\
\hline 40 & CC8-A-2 & 108 & 6.5 & 853 & 21.5 & 2275 & 2768 & 1.22 \\
\hline 41 & CC8-A-4-1 & 109 & 6.5 & 853 & 33.1 & 2446 & 2882 & 1.18 \\
\hline 42 & CC8-A-4-2 & 108 & 6.5 & 853 & 33.1 & 2402 & 2851 & 1.19 \\
\hline 43 & CC8-A-8 & 108 & 6.5 & 853 & 61.2 & 2713 & 3050 & 1.12 \\
\hline 44 & CC8-C-2 & 222 & 6.5 & 843 & 21.5 & 4964 & 6254 & 1.26 \\
\hline 45 & CC8-C-4-1 & 222 & 6.5 & 843 & 33.1 & 5638 & 6654 & 1.18 \\
\hline 46 & CC8-C-4-2 & 222 & 6.5 & 843 & 33.1 & 5714 & 6654 & 1.16 \\
\hline 47 & CC8-C-8 & 222 & 6.5 & 843 & 61.2 & 7304 & 7617 & 1.04 \\
\hline 48 & CC8-D-2 & 337 & 6.5 & 823 & 21.5 & 8475 & 10045 & 1.19 \\
\hline 49 & CC8-D-4-1 & 337 & 6.5 & 823 & 33.6 & 9668 & 11044 & 1.14 \\
\hline 50 & CC8-D-4-2 & 337 & 6.5 & 823 & 33.6 & 9835 & 11044 & 1.12 \\
\hline 51 & CC8-D-8 & 337 & 6.5 & 823 & 67.6 & 13776 & 13849 & 1.01 \\
\hline
\end{tabular}

Thus, the composite strength of CFST column considering the age is simplified as shown in Eq.(20), in which $M=0.001 \xi_{s c}(t)+0.2 \alpha$.

$$
f_{s c}(t)=\left[1+\frac{\xi_{s c}(t)}{[2+M]\left(1+\xi_{s c}(t)\right)}\right]\left[(1-\beta) f_{c k}(t)+\beta f_{y}\right]
$$

In practice, the range of steel grade is Q235 to Q420, and concrete is C30 to C80, the range of $f_{y} / f_{c k}(t)$ is 4.7 to 20.9. The range of steel ratio of CFST is from 0.04 to 0.2 , Thus, the range of $M$ is from 0.008 to 0.04 and $1 /(2+M) \approx 0.5$. Also according to ACI209 [24], there is a relationship between the strength of hardened and hardening concrete,

$f_{c k}(t)=Q(t) f_{c k}$

$Q(t)=\frac{t}{4+0.85 t}$

Then, the composite strength of CFST column considering concrete age can be expressed as following,

$$
\begin{aligned}
& f_{s c}(t)=\left[1+\frac{0.5 \xi_{s c}(t)}{\left(1+\xi_{s c}(t)\right)}\right]\left[(1-\beta) f_{c k}(t)+\beta f_{y}\right]=\frac{Q(t)+1.5 \xi_{s c}^{0}}{1+\alpha} f_{c k} \\
& =\frac{\frac{t}{4+0.85 t}+1.5 \xi_{s c}^{0}}{1+\alpha} f_{c k}
\end{aligned}
$$

In which, $\xi_{s c}^{0}=\alpha f_{y} / f_{c k}$, and $f_{c k}$ is the strength of hardened concrete. 


\section{Experiments and FE Analysis}

In order to validate the formula of composite strength of CFST column considering concrete age of different hardening time, experiments and FEM are used in this section.

\subsection{FE Model of CFST Columns}

The software Abaqus is adopted to establish the FE Model. In the model, the 8-node quadrilateral in-plane general purpose continuum shell element (SC8R) is used for the steel tube, and the 8-node linear brick element (C3D8R) is used for the concrete. The bilinear material model is adopted for the steel, with the tangent modulus being one percent of the Elastic Modulus of 206GPa. The material model of the concrete is the damaged plasticity (DP) model with dilation angle being $40^{\circ}$, and the strength of the concrete at different hardening time follows the curves proposed by Yi [25], as Eq. (24). Other material and geometrical parameters of the column are given in Table 2. According to the experimental specimen in Figure 2, the FE meshes of a typical CFST column are shown in Figure 3. It is assumed that the contact between the steel tube and the concrete is perfect. In order to study the convergent of the FEM model, different meshing schemes are tried which are listed in Table 3.

$$
\begin{aligned}
& f_{c}(t)=\frac{\beta_{m}\left(\varepsilon_{c} / \varepsilon_{c}^{\prime}\right)}{\beta_{m}-1+\left(\varepsilon_{c} / \varepsilon_{c}^{\prime}\right)^{\beta_{m}}} f_{c}^{\prime} \\
& \beta_{m}=\beta_{m, a}=\left[1.02-1.17\left(E_{0} / E_{c}\right)\right]^{-0.74}, \varepsilon_{c}<\varepsilon_{c}^{\prime} \\
& \beta_{m}=\beta_{m, d}=\beta_{m, a}+(a+b t), \varepsilon_{c} \geq \varepsilon_{c}^{\prime} \\
& a=\left(12.4-1.66 \times 10^{-2} f_{c, 28}\right)^{-0.46} \\
& b=0.83 \exp \left(-911 / f_{c, 28}\right)
\end{aligned}
$$

Where,

$t \quad-\quad$ the age of concrete in day;

$f_{c}(t), \varepsilon_{c}-\quad$ concrete stress and strain to be computed;

$f_{c}^{\prime}, \varepsilon_{c}^{\prime} \quad$ maximum stress and corresponding strain of concrete at $t$ days;

$E_{0} \quad$ the secant modulus at the maximum stress, $E_{0}=f_{c}^{\prime} / \varepsilon_{c}^{\prime}$;

$E_{c} \quad-\quad$ elastic modulus of concrete;

$\beta_{m, a} \quad \_$a parameter of concrete for the ascending branch;

$\beta_{m, d} \quad \_$a parameter of concrete for the descending branch. 


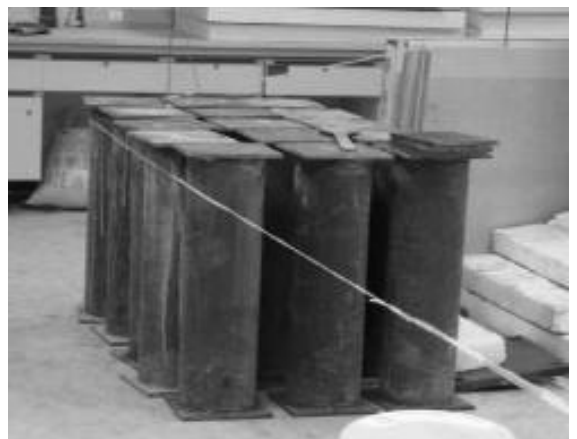

Figure 2. Experimental Specimens of CFST

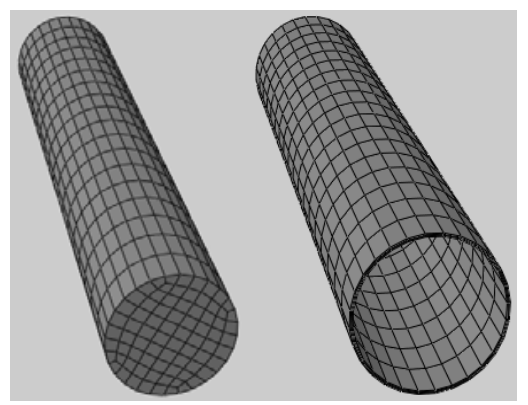
a) concrete
b) Steel tube

Figure 3. Finite Element Mesh of CFST Member

Table 2. Geometry and Material Parameters of CFST Column

\begin{tabular}{|c|c|c|c|c|c|}
\hline$D(\mathrm{~mm})$ & $T(\mathrm{~mm})$ & $L(\mathrm{~mm})$ & $f_{y}(\mathrm{MPa})$ & $f_{c k}(\mathrm{MPa})$ & $E_{s}(\mathrm{MPa})$ \\
\hline 219 & 5.5 & 766 & 355 & 51.2 & $2.06 \mathrm{e} 5$ \\
\hline 133 & 4.5 & 400 & 345 & 40.8 & $2.06 \mathrm{e} 5$ \\
\hline
\end{tabular}

Table 3. The Ultimate Load of Different Meshing Scheme

\begin{tabular}{|c|c|c|c|c|c|c|c|}
\hline Model & N-Ring & N-Radius & N-Axial & E-Section & E-Tolal & N-3d (kN) & N-28d (kN) \\
\hline M1 & 12 & 2,3 & 18 & 56 & 1120 & 2240 & 2868 \\
\hline M2 & 12 & 3,4 & 18 & 68 & 1224 & 2256 & 2904 \\
\hline M3 & 16 & 3,4 & 18 & 96 & 1728 & 2285 & 2942 \\
\hline M4 & 20 & 3,4 & 18 & 104 & 1872 & 2358 & 2965 \\
\hline M5 & 24 & 3,4 & 18 & 132 & 2376 & 2372 & 2972 \\
\hline M6 & 28 & 3,4 & 18 & 160 & 2880 & 2377 & 2979 \\
\hline
\end{tabular}

In Table 3, N-Ring, N-Radius, and $\mathrm{N}$-Axial are the respective numbers of elements in the circumferential, radial, and axial directions. E-Section and E-Total are the total numbers of elements on a cross section and of the whole column, respectively. N-3d and N-28d are the ultimate axial loads of the column at the age of 3 and 28 days. It can be seen that when the element mesh is finer than M4, smaller difference between the different meshing schemes are observed. It is decided therefore that the mesh scheme M4 will be used in the following numerical simulations. 


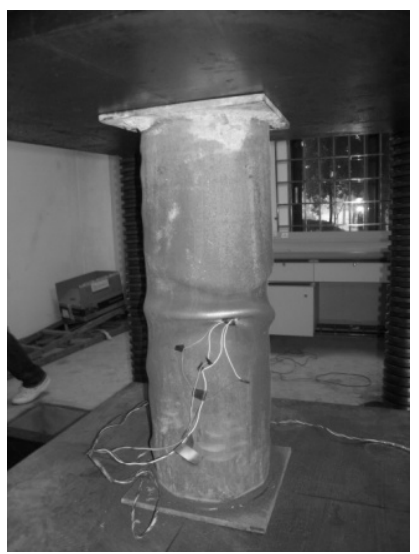

Figure 4. Load Bearing Capacity Experiment of the CFST Column

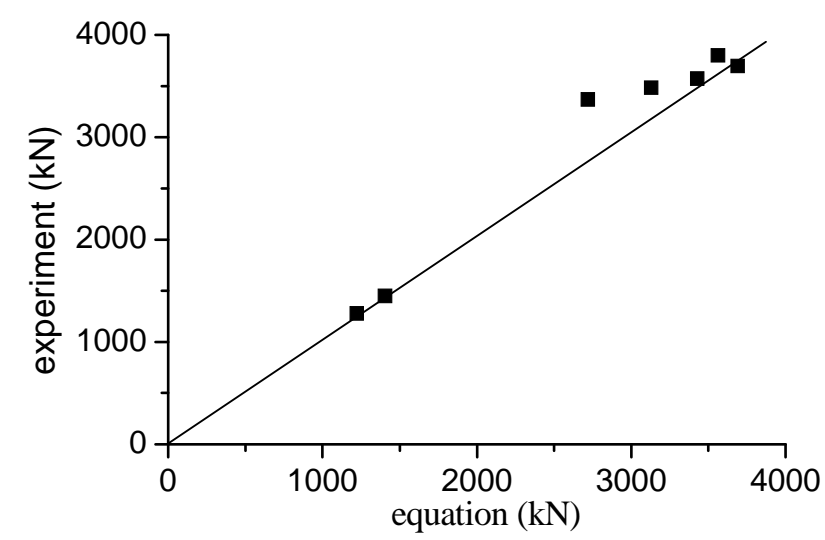

Fig.5 calculated value compared with experiment

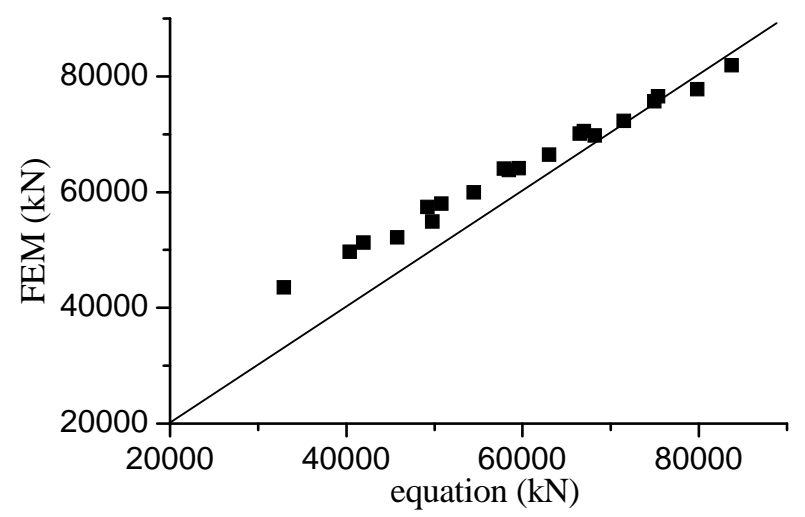

Figure 6. Calculated Value Compared with FEM

\subsection{Validation of the Formula}

Laboratory experiments had been carried out, as shown in Figures 2 and 4, and the specimen configuration details are specified in Table 2 . The load bearing capacity experiments were taken at the concrete curing ages of $3,7,14,21,35$ and 49 days.

The experimental results of the time-dependent elastic modulus of concrete at different ages are shown in Table 4. The comparison between equation results $N_{c}$, experimental results $N_{t}$ and FE results $N_{f}$ are showed in Table 5, 6 and Figure 5, 6. And the mean value is 0.945 and standard deviation is 0.06 which indicate the formula can predict well the composite strength of CFST columns by considering the variation of concrete curing age. 
Table 4. Elastic Modulus of the Concrete at Different Age

\begin{tabular}{|c|c|c|c|c|c|}
\hline age(day) & 3 & 7 & 14 & 21 & 28 \\
\hline$E_{c}(\mathrm{MPa})$ & 30680 & 32319 & 34053 & 35101 & 35905 \\
\hline
\end{tabular}

Table 5. Further Comparisons of Analytical Results with the Tests Results

\begin{tabular}{|c|c|c|c|c|c|c|c|c|c|}
\hline No. & $\begin{array}{c}\mathrm{D} \\
/ \mathrm{mm}\end{array}$ & $\begin{array}{c}\mathrm{T} \\
/ \mathrm{mm}\end{array}$ & $\begin{array}{c}\mathrm{f}_{\mathrm{y}} \\
/ \mathrm{MPa}\end{array}$ & $\begin{array}{c}\mathrm{f}_{\mathrm{ck}} \\
/ \mathrm{MPa}\end{array}$ & $\begin{array}{c}\mathrm{t} \\
/ \mathrm{day}\end{array}$ & $\begin{array}{c}\mathrm{f}_{\mathrm{sc}} \\
/ \mathrm{MPa}\end{array}$ & $\begin{array}{c}\mathrm{N}_{\mathrm{c}} \\
/ \mathrm{kN}\end{array}$ & $\begin{array}{c}\mathrm{N}_{\mathrm{t}} \\
/ \mathrm{kN}\end{array}$ & $\mathrm{N}_{\mathrm{c}} / \mathrm{N}_{\mathrm{t}}$ \\
\hline 1 & 219 & 5.5 & 355 & 22.626 & 3 & 72.21 & 2719 & 3368.3 & 0.807 \\
\hline 2 & 219 & 5.5 & 355 & 34.754 & 7 & 83.15 & 3131 & 3484 & 0.899 \\
\hline 3 & 219 & 5.5 & 355 & 43.497 & 14 & 91.04 & 3428 & 3572.7 & 0.959 \\
\hline 4 & 219 & 5.5 & 355 & 47.478 & 21 & 94.63 & 3563 & 3797.7 & 0.938 \\
\hline 5 & 219 & 5.5 & 355 & 51.230 & 35 & 98.02 & 3690 & 3694.7 & 0.999 \\
\hline 6 & 219 & 5.5 & 355 & 53.025 & 49 & 99.64 & 3751 & 3802.3 & 0.987 \\
\hline 7 & 133 & 4.5 & 345 & 28.704 & 7 & 87.92 & 1221 & 1276 & 0.956 \\
\hline 8 & 133 & 4.5 & 345 & 40.80 & 53 & 101.3 & 1406 & 1447 & 0.972 \\
\hline
\end{tabular}

Table 6. Further Comparisons of Analytical Results with FEM Results

\begin{tabular}{|c|c|c|c|c|c|c|c|c|c|}
\hline No. & $\begin{array}{c}\mathrm{D} \\
/ \mathrm{mm}\end{array}$ & $\begin{array}{c}\mathrm{T} \\
/ \mathrm{mm}\end{array}$ & $\begin{array}{c}\mathrm{f}_{\mathrm{y}} \\
/ \mathrm{MPa}\end{array}$ & $\begin{array}{c}\mathrm{f}_{\mathrm{ck}} \\
/ \mathrm{MPa}\end{array}$ & $\begin{array}{c}\mathrm{t} \\
/ \mathrm{day}\end{array}$ & $\begin{array}{c}\mathrm{f}_{\mathrm{sc}} \\
/ \mathrm{MPa}\end{array}$ & $\begin{array}{c}\mathrm{N}_{\mathrm{c}} \\
/ \mathrm{kN}\end{array}$ & $\begin{array}{c}\mathrm{N}_{\mathrm{f}} \\
/ \mathrm{kN}\end{array}$ & $\mathrm{N}_{\mathrm{c}} / \mathrm{N}_{\mathrm{f}}$ \\
\hline 1 & 1000 & 12 & 345 & 18.641 & 3 & 41.95 & 32930 & 43497 & 0.757 \\
\hline 2 & 1000 & 12 & 345 & 28.633 & 7 & 51.47 & 40402 & 49731 & 0.812 \\
\hline 3 & 1000 & 12 & 345 & 35.836 & 14 & 58.33 & 45789 & 52161 & 0.878 \\
\hline 4 & 1000 & 12 & 345 & 40.993 & 28 & 63.42 & 49781 & 54934 & 0.906 \\
\hline 5 & 1000 & 18 & 345 & 18.641 & 3 & 53.41 & 41923 & 51250 & 0.818 \\
\hline 6 & 1000 & 18 & 345 & 28.633 & 7 & 62.69 & 49213 & 57432 & 0.857 \\
\hline 7 & 1000 & 18 & 345 & 35.836 & 14 & 69.39 & 54467 & 59979 & 0.908 \\
\hline 8 & 1000 & 18 & 345 & 40.993 & 28 & 74.42 & 58422 & 63839 & 0.915 \\
\hline 9 & 1000 & 24 & 345 & 18.641 & 3 & 64.70 & 50789 & 58000 & 0.876 \\
\hline 10 & 1000 & 24 & 345 & 28.633 & 7 & 73.76 & 57898 & 64098 & 0.903 \\
\hline 11 & 1000 & 24 & 345 & 35.836 & 14 & 80.28 & 63023 & 66483 & 0.948 \\
\hline 12 & 1000 & 24 & 345 & 40.993 & 28 & 85.29 & 66955 & 70591 & 0.948 \\
\hline 13 & 1000 & 30 & 345 & 18.641 & 3 & 75.86 & 59553 & 64129 & 0.929 \\
\hline 14 & 1000 & 30 & 345 & 28.633 & 7 & 84.69 & 66484 & 70131 & 0.948 \\
\hline 15 & 1000 & 30 & 345 & 35.836 & 14 & 91.06 & 71480 & 72343 & 0.988 \\
\hline 16 & 1000 & 30 & 345 & 40.993 & 28 & 96.03 & 75382 & 76533 & 0.985 \\
\hline 17 & 1000 & 36 & 345 & 18.641 & 3 & 86.87 & 68195 & 69795 & 0.977 \\
\hline 18 & 1000 & 36 & 345 & 28.633 & 7 & 95.48 & 74950 & 75706 & 0.990 \\
\hline 19 & 1000 & 36 & 345 & 35.836 & 14 & 101.68 & 79819 & 77777 & 1.026 \\
\hline 20 & 1000 & 36 & 345 & 40.993 & 28 & 106.63 & 83702 & 81960 & 1.021 \\
\hline
\end{tabular}




\section{CONCLUSION}

In the paper, an analytical solution was presented for composite strength of CFST columns considering the influence of concrete age of different hardening time. Bearing capacity experiments of CFST columns with different concrete age were conducted, and FM method was used to calculate the strength of CFST columns with different concrete aging time, steel ratio and concrete strength. Comparisons of composite strength between the formula, the experiment and the FE method results were made, which showed that the formula can predict the composite strength of CFST column well.

For the further work, it is needed to develop the formula of the stability property of CFST column considering the concrete age based on the one presented in this paper.

\section{REFERENCES}

[1] Tomii, M., Yoshimura, K. and Morishita, Y., "Experimental Studies on Concrete Filled Steel Tubular Stub Column under Concentric Loading”, Proceedings of the International Colloquium on Stability of Structures under Static and Dynamic Loads, Washington, USA, 1977, pp. 718-741.

[2] Schneider, S.P., “Axially Loaded Concrete-filled Steel Tubes”, J. Struct. Eng., 1998, Vol. 124, No. 10, pp. $1125-1138$.

[3] O'Shea, M.D. and Bridge, R.Q., "Design of Circular Thin-walled Concrete Filled Steel Tubes”, J. Struct. Eng., 2000, Vol. 126, No. 11, pp. 1295-1303.

[4] Giakoumelis, G. and Lam, D., "Axial Capacity of Circular Concrete-filled Tube Columns”, J. Constr. Steel Res., 2004, Vol. 60, No. 7, pp. 1049-1068.

[5] Zhong, S.T., “The Concrete-Filled Steel Tubular Structures”, Tsinghua Univ. Press, 2005. (In Chinese)

[6] Cai, Sh. H., "Modern Concrete Filled Steel Tubular Structure”, China Communications Press, 2007. (In Chinese)

[7] Zha, X.X., "Hollow and Solid Concrete-filled Steel Tube Columns Structure”, Science Press, 2011. (In Chinese)

[8] Han, L.H., “Concrete Filled Steel Tube Structure: Theory and Practice”, Science Press, 2007. (In Chinese)

[9] Fu, X.Y., "The Simulated Calculation of Highrise Building Structure under Vertical Construction Loads”, J. Shenzh. Univ. (Science \& Engineering), 2003, Vol. 20, No. 4, pp. 8-13. (In Chinese)

[10] Fan, F., Wang, H.J. and Zhi, X.D., “Analysis of Vertical Deformation During Construction of the Shanghai World Financial Center”, J. Build Struct., 2010, Vol. 31, No.7, pp. 118-124. (In Chinese)

[11] Duan, X. Sh., Zhou, X.Y. and Chang, Y. Ch., "Stress Monitoring and Numerical Analysis in Construction Process for Tianjin Tower”, J. Build Struct., 2011, Vol. 41, No. 6, pp. 114-117. (In Chinese)

[12] Tan, S.J. and Qi, J.L., "Experimental Investigation of the Effect on the Strength of Concrete Filled Steel Tubular Compressive Members under Long-term Load”, J. Harb. Eng. Univ., 1987, No. 2, pp. 10-24. (In Chinese)

[13] Nakai, H., Kurita, A. and Ichinose, L.H., "An Experimental Study on Creep of Concrete Filled Steel Pipes”, Proceeding of the 3rd International Conference on Composite Construction in Steel and Concrete, 1991, pp. 55-60. 
[14] Terry, P.J., Bradford, M.A. and Gilbert, R.I., "Creep and Shrinkage in Concrete Filled Steel Tubes”, Proceeding of the 6th International Symposium in Tubular Structures, 1994, pp. 293-298.

[15] Ichinose, L.H., Watanabe, E. and Nakai, H., “An Experimental Study on Creep of Concrete Filled Steel Pipes”, J. Constr. Steel Res., 2001, Vol. 57, No. 4, pp. 453-466.

[16] Kwon, S.H., Kim, Y.Y. and Kim, J. K., "Long-term Behaviour under Axial Service Loads of Circular Columns Made from Concrete Filled Steel Tubes”, Magaz. Concr. Res., 2005, Vol. 57, No. 2, pp. 87-99.

[17] Acar, M.H., "Evaluation of Creep Coefficient on Concrete-filled Steel Tubular Columns”, J. Eng. Mat. Scienc., 2007, Vol. 14, No. 4, pp. 295-302.

[18] Yu, M., Zha, X.X. and Ye, J., “A Unified Formulation for Hollow and Solid Concrete-filled Steel Tube Columns under Axial Compression”, Engin. Struct., 2010, Vol. 32, No. 4, pp. 1046-1053.

[19] Budynas, R.G., “Advanced Strength and Applied Stress Analysis”, Engin. Mechan. Scienc., 1998.

[20] Sadd, M.H., “Elasticity: Theory, Applications, and Numerics”, Acad. Press, 2004.

[21] Oluokun, F.A., Burdette, E.G. and Deatherage, J.H., "Elastic Modulus, Poisson’s Ratio, and Compressive Strength Relationship at Early Ages”, ACI Mater J, 1991, Vol. 88, No. 1, pp. 3-9.

[22] Carmichael, R.P., "Relationship between Young's Modulus, Compressive Strength, Poisson' Ratio, and Time for Early Age”, Swarth Colleg. Depart. Engin., 2009.

[23] Kenji, S., Hiroyuki, N., Shosuke, M. and Isao, N., "Behavior of Centrally Loaded Concrete Filled Steel-tube Short Columns”, J. Struct. Eng.-ASCE, 2004, Vol. 130, No. 2, pp. 180-188.

[24] American Concrete Institute (ACI) 209, "Prediction of Creep, Shrinkage, and Temperature Effects in Concrete Structures (ACI209R-92)”, ACI Committee 209R, 1992.

[25] Yi, S.T., Kim, J.K. and Oh, T.K., "Effect of Strength and Age on the Stress-strain Curve of Concrete Specimens”, Cem. Concr. Res., 2003, Vol. 33, No.8, pp. 1235-1244. 